\title{
Lobectomy or sublobar resection? - comparative analysis of the techniques in the surgical treatment of non-small cell lung cancer: a narrative review
}

\author{
Duilio Divisi^, Andrea De Vico, Piero Aquilini, Gino Zaccagna \\ Department of MeSVA, University of L'Aquila, Thoracic Surgery Unit, “Giuseppe Mazzini” Hospital, Teramo, Italy \\ Contributions: (I) Conception and design: D Divisi, G Zaccagna; (II) Administrative support: None; (III) Provision of study materials or patients: A De \\ Vico, G Zaccagna; (IV) Collection and assembly of data: D Divisi, A De Vico, G Zaccagna; (V) Data analysis and interpretation: P Aquilini, D Divisi, \\ G Zaccagna; (VI) Manuscript writing: All authors; (VII) Final approval of manuscript: All authors. \\ Correspondence to: Prof. Duilio Divisi, MD, PhD. Thoracic Surgery Unit, University of L'Aquila, “G. Mazzini” Hospital of Teramo, Teramo, Italy. \\ Email: duilio.divisi@aslteramo.it; duilio.divisi@univaq.it.
}

\begin{abstract}
Objective: The aim of the study is to compare two techniques in the surgical treatment of resectable nonsmall cell lung cancer (NSCLC).

Background: Minimally invasive surgery is the gold standard in the treatment of lung cancer in the early stage. This strategy is not only related to the reduced surgical access but also to the amount of parenchyma that must be saved, compatibly with the oncological radicality. The purpose of the study is to evaluate if sublobar resection can be a valid alternative to lobectomy, based on results.

Methods: We carried out a systematic analysis of the studies conducted in literature in the last 6 years (from 2015 to 2021), comparing the outcomes of lobectomies and sublobar resections (segmentectomy or wedge). The parameters considered were as follows: complications, relapse rate and overall survival. Lobectomy showed a slightly higher risk of developing complications than sublobar resection, especially in octogenarian or in a high index of comorbidity $(0-48 \%$ vs. $0-46.6 \%$, respectively). Conversely, the relapse rate $(2.3-32 \%$ vs. $2.9-53.4 \%$ ) and overall survival (45.9-93.8\% vs. 33.8-100\%) were more favorable in patients treated with lobectomy although sublobar resection showed an increasing survival rate over the years.

Conclusions: From the review of literature, lobectomy is still the safest oncologically method to treat the bronchogenic carcinoma. Regarding sublobar resections, there is no clear and distinct classification of results between anatomical segmentectomy and wedge resection. More multicenter randomized studies would be needed in order to compare the three techniques separately.
\end{abstract}

Keywords: Lung cancer; surgical treatment; outcomes; analytic review

Received: 11 May 2021; Accepted: 20 July 2021; Published: 30 December 2021.

doi: 10.21037/asj-21-31

View this article at: https://dx.doi.org/10.21037/asj-21-31

\section{Introduction}

In recent years we have witnessed a continuous technological evolution and the constant development of genetic research, in order to offer targeted medical therapy (1-3) in non-small cell lung cancer (NSCLC). However, the most effective treatment still remains the surgical approach. If the aim of lung cancer surgery is to achieve the oncological radicality, an adequate resection of parenchyma is mandatory to obtain expected results. This decision must also consider

$\wedge$ ORCID: 0000-0002-8137-7533. 


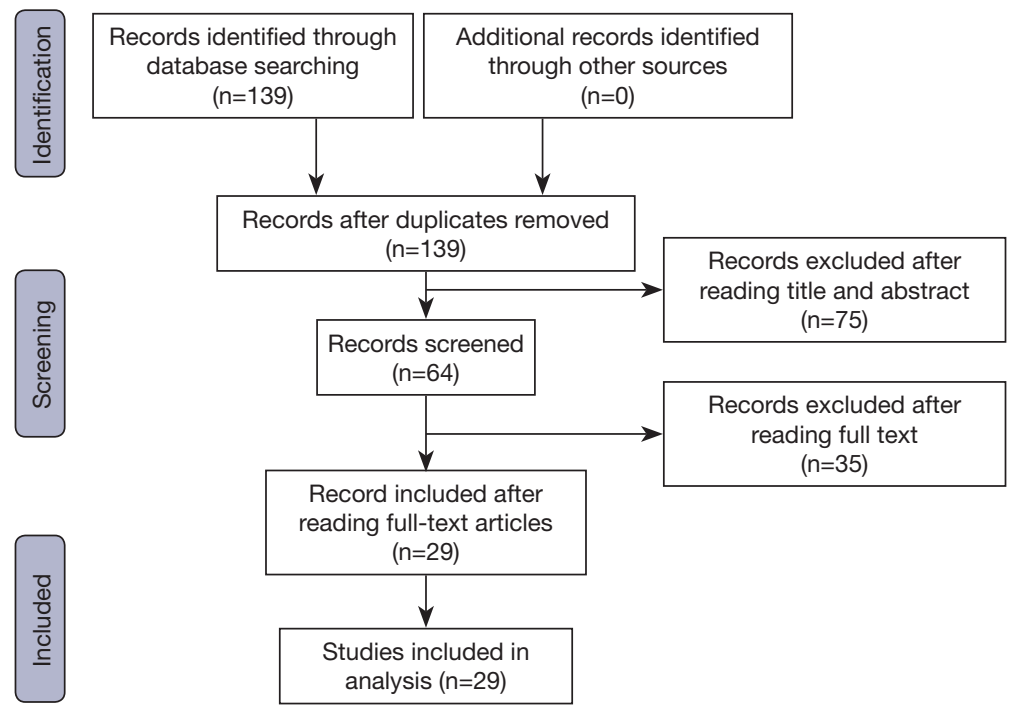

Figure 1 Flow chart of included studies.

the lengthening of average overall survival (4) due to the improvement of the lifestyle and the state of well-being. In fact, comorbidities and other risk factors are evaluated in patients over a hundred years old (5). Limited resections have been proposed in patients whose clinical condition did not allow for major resection $(6,7)$. However, the fundamental question is whether major resections are the right choice in the treatment of early-stage lung cancer regardless to age, comorbidities or general health of the patients (8-10). The study, starting from the evaluation of the results, tries to quantify the risks and benefits of sublobar resections compared to lobectomies $(11,12)$. The analysis was carried out on literature data, in order to understand if parenchyma saving is the way forward. We present the following article in accordance with the Narrative Review reporting checklist (available at https://asj.amegroups.com/article/ view/10.21037/asj-21-31/rc).

\section{Methods}

The purpose of the study is to analytically establish the safety of the lung resection techniques in NSCLC, comparing the literature data.

The search was carried out using a combination of words, relevant $\mathrm{MeSH}$ terms and appropriate filters; the strategy was developed in MEDLINE (via PubMed) from 2015 to 2021. A specific software was used for the management of the records identified with the selected search criteria. As search terms we used: "non-small cell lung cancer AND lobectomy AND/OR sublobar resection AND outcomes". Based on the eligibility criteria, the studies were evaluated by two independent authors who also analyzed the literature and assessed the dissimilarities; any biases were discussed and resolved. A flow chart was created with the included and excluded items. The experiences that contained overlapping data were discussed. Any discrepancies they were resolved by consensus after extensive discussion. The following elements were extracted from each study, if available: first author surname, year of publication, surgical strategy, relapse, complications, 5-year overall survival.

The comparative analysis of the values relating to the different parameters provide an evaluation index of the safety of the methods. Finally, the data were graphically reported with Microsoft Excel in order to make the results evaluable and more easily analyzed.

\section{Results}

One hundred and forty-two results were obtained and, after removing the duplicates and non-English articles, 139 articles were identified. After reading the abstract, 75 studies out of 139 were excluded because not relevant. Of the remaining 64 articles, only 29 were considered relevant after evaluating the content of the full text and included in the data analysis (Figure 1); 9 are the most recent articles, published from 2019 to 2021 [(13-21), Table 1] and 20 published in the 3 -year period 2015-2018 [(22-41), Table 2]. Information on 48,365 
patients treated for resectable NSCLC (stage I-II) were collected. Of these, 29,789 patients underwent lobectomy and 18,576 underwent sublobar resection (wedge or anatomic segmentectomy). We divided the patients according to the year of publication of the studies and then we classified the three parameters separately according to the procedure performed. The parameters considered were as follows: complications, relapse and overall survival. Comparing sublobar resections and lobectomies, the noted outcomes are the following (Tables 1,2): (I) incidence of complication ranged from $0 \%$ and $46.6 \%$ vs. $0 \%$ and $48 \%$, respectively; (II) incidence of relapses ranged from $2.9 \%$ and $53.4 \%$ vs. from $2.3 \%$ and $32 \%$, respectively; (III) 5 -year overall survival ranged from $33.8 \%$ to $100 \% v s$. from $45.9 \%$ to $93.8 \%$, respectively. Therefore, sublobar resections are characterized by a reduced complication rate but showed a greater risk of developing relapses with a reduction in overall survival compared to lobectomies. Then, we used Microsoft Excel to analyze these values as a function of time. We obtained the curves of survival comparing the outcomes related to patients undergoing lobectomy (Figure 2) and to patients undergoing sublobar resection (Figure 3). Analyzing the two curves in a system we notice that the disadvantage of sublobar resections in terms of survival decreasing as a function of time (Figure 4). The data are interpreted in a critical sense, not being able to perform a meta-analysis. There are no major differences between the techniques but the data still show a trend that can lead the choice based on the experience of different centers.

\section{Discussion}

In the surgical treatment (42) of early stages NSCLC, pulmonary lobectomy has always considered the gold standard $(43,44)$. However, the debate about the role of sublobar resections in these patients is particularly heated in recent years (45). Sparing of pulmonary parenchyma is widely accepted in the treatment of subsolid malignant nodules, but the effectiveness remains controversial in consideration of several factors (46-48). One of these is the tumor spread through air spaces (STAS); the role of STAS in the prognosis of patients undergoing sublobar resections was studied by Zhang et al. (17). They have studied 108 patients of whom 58 underwent lobectomy and 50 sublobar resection. Patients showed nodules $\leq 2 \mathrm{~cm}$ and one of the following characteristics: (I) adenocarcinoma in situ; (II) ground glass opacity with solid component $>50 \%$; (III) doubling time $>400$ days. The authors highlighted that the differences between the two groups concerned only drainage time, hospital stay and costs. On the other hand, they found no significant differences in terms of efficacy on the basis of the following parameters: (I) STAS; (II) lymph node, vascular or pleural involvement; (III) short-term complications. According to what has been described, the techniques would be equally effective but long-term data such as relapse rate and overall survival are not reported by authors. We disagree with those conclusions as we think that STAS is associated with possible long term relapse.

For this reason, in our analysis, we considered a 5-year overall survival. Another justification for choosing sublobar resection seems to be the subsolid nature of nodules.

Im et al. (13) carried out a prospective multicenter observational study on 173 patients with stage IA lung adenocarcinoma. Patients were selected from 250 with radiological evidence of ground glass opacity (part solid nodules and pure ground glass). Of these, 63 underwent pulmonary lobectomy and 110 sublobar resection. The goal was to assess the relapse rate in the two groups which proved to be overlapping ( $2.3 \%$ vs. $2.6 \%)$ over a followup of 5 years on average. However, the same authors admit the existence of biases in the study: (I) firstly, the recurrence rate was too low; (II) secondly, patients were not assigned uniformly in the groups; (III) thirdly, in 24 patients underwent sublobar resection no lymph node dissection was performed. We opine that the radiological characteristics of the nodules alone cannot justify a sublobar resection. Furthermore, the recurrence of disease can be linked to lymph node micrometastases not radiologically identified. Then, it is also important to perform a systematic nodal dissection in patients undergoing sublobar resection.

Wald et al. (14) studied 162 T1N0 NSCLC patients, from 2008 to 2018, of which 107 underwent lobectomy and 55 segmentectomy or wedge resection. Lymph node dissection was performed in all lobectomies and in $85 \%$ of sublobar resections. Sublobar resection compared to lobectomy showed a slightly higher 5-year survival rate (75.9\% vs. $71.8 \%)$; Authors suggested that, in selected patients, the effectiveness of this technique is comparable to lobectomy. The most frequently detected complications were: (I) airway infections or pneumonia; (II) changes in heart rhythm (atrial fibrillation); (III) alteration of white blood cells, platelets or hemoglobin; (IV) limited bleeding; (V) prolonged air leaks. Other types of complications found less frequently: (I) chylothorax; (II) kidney failure; (III) bleeding requiring reintervention; (IV) respiratory failure requiring re-intubation; (V) acute coronary syndrome; (VI) 
Table 1 Selected papers (13-21) from 2019 to 2021 for the comparison between lobectomy and sublobar resection

\begin{tabular}{|c|c|c|c|c|c|}
\hline Author, year & $\begin{array}{c}\text { Number of patients/ } \\
\text { procedures }\end{array}$ & Type of resection & Complications & $\begin{array}{l}\text { Incidence of } \\
\text { recurrence }\end{array}$ & Overall survival \\
\hline Im et al. 2021 & 173 & 63 lobectomy; 110 sublobar & - & $2.3 \% ; 2.9 \%$ & - \\
\hline Wald et al. 2021 & 162 & 107 lobectomy; 55 sublobar & - & - & $71.8 \% ; 75.9 \%$ \\
\hline Dong et al. 2020 & 121 & Sublobar & $22 \%$ & - & $82.8 \%$ \\
\hline Chang et al. 2019 & 364 & Segmentectomy & $4.1-8.5 \%$ & $4.1 \%$ & - \\
\hline Amiraliev et al. 2019 & 200 & $\begin{array}{l}148 \text { lobectomy; } 52 \\
\text { segmentectomy }\end{array}$ & - & - & $82 \% ; 86 \%$ \\
\hline
\end{tabular}

Table 2 Selected papers (22-41) from 2015 to 2018 for the comparison between lobectomy and sublobar resection

\begin{tabular}{|c|c|c|c|c|c|}
\hline Author, year & $\begin{array}{c}\text { Number of patients } \\
\text { procedures }\end{array}$ & Type of resection & Complications & $\begin{array}{l}\text { Incidence of } \\
\text { recurrence }\end{array}$ & Overall survival \\
\hline Yang et al. 2018 & 4,866 & Sublobar & - & - & $58.5 \%$ \\
\hline Ali et al. 2018 & 242 & Segmentectomy & $8.26 \%$ & & $100 \%$ \\
\hline Yendamuri et al. 2018 & 3,916 & Sublobar & - & - & $65.8 \%$ \\
\hline Moon et al. 2018 & 133 & Sublobar & - & - & $49.9-100 \%$ \\
\hline Gossot et al. 2017 & 284 & Segmentectomy & $15.3 \%$ & - & - \\
\hline Tsunezuka et al. 2017 & 62 & Sublobar (wedge) & - & $53.4 \%$ & $56.4 \%$ \\
\hline Fiorelli et al. 2016 & 239 & 149 lobectomy; 90 sublobar & & $19 \% ; 23 \%$ & $60.5 \% ; 45 \%$ \\
\hline Gulak et al. 2016 & 5,749 & 4,424 lobectomy; 1,325 sublobar & $0-8.7 \% ; 0-9.5 \%$ & - & - \\
\hline Dai et al. 2016 & 15,760 & 11,520 lobectomy; 4,240 sublobar & - & - & HR: $1.37 / 1.83$ \\
\hline Kent et al. 2016 & 212 & Sublobar & - & - & $58.4 \%$ \\
\hline Razi et al. 2016 & 1,640 & 1,051 lobectomy; 589 sublobar & - & - & $\begin{array}{c}50.2 \% \\
38.6-43.8 \%\end{array}$ \\
\hline Hattori et al. 2016 & 115 & Sublobar & - & $<27.8 \%$ & $82.2 \%$ \\
\hline
\end{tabular}

$\mathrm{HR}$, hazard ratio. 


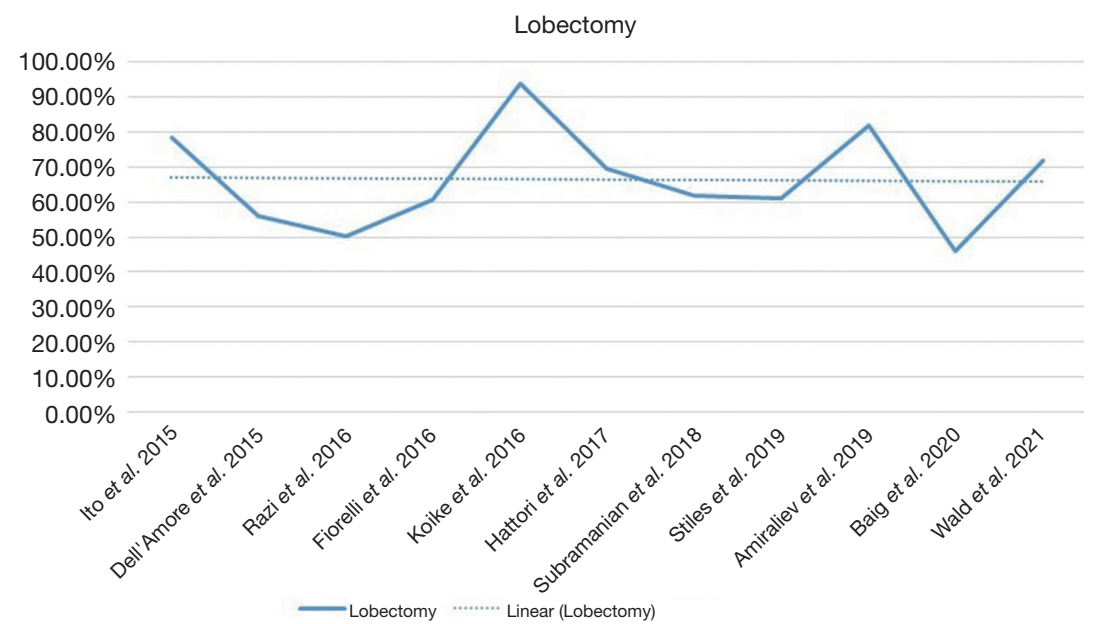

Figure 2 Trend of the survival curve for lobectomies.

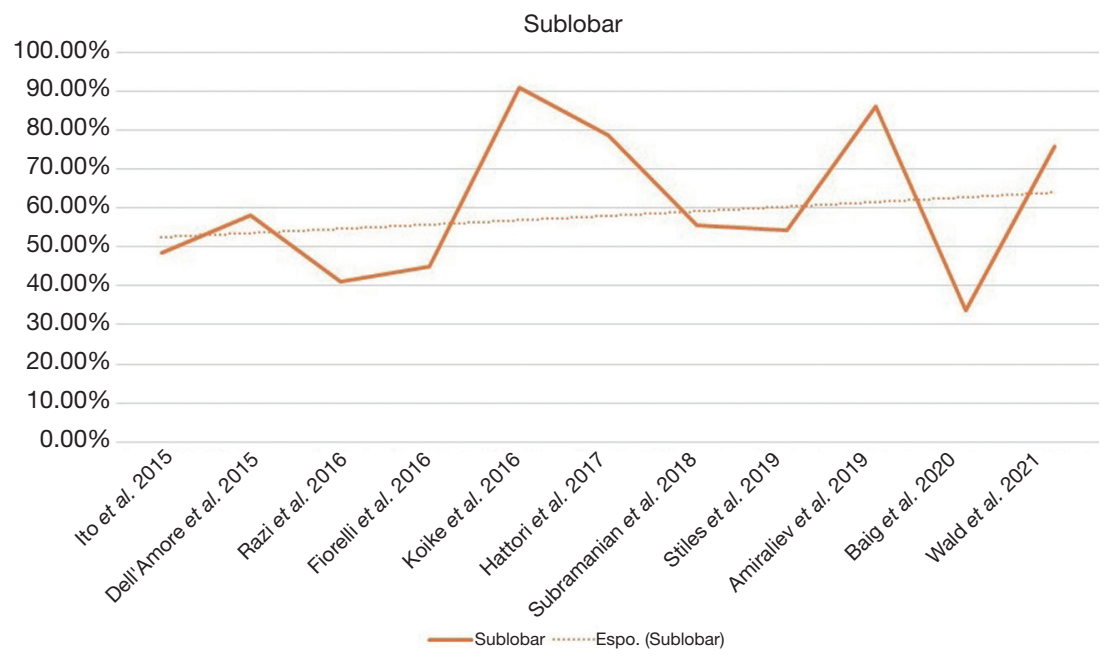

Figure 3 Trend of the survival curve for sublobar resection.

pulmonary embolism $(32,39,40)$. In our study we noted that some authors showed a complication rate $<1 \%$ while others displayed values $>40 \%$. In consideration of these heterogeneous data in the literature, we can state that it is not possible to establish the advantages and disadvantages of a sublobar resection compared to a lobectomy in the treatment of early-stage NSCLC. Often, the outcomes of wedge resections are not clearly distinct from those of anatomical segmentectomies, so it is impossible to define the role and limits of these methods. Cao et al. (49) and Zhang et al. (50) carried out meta-analysis in order to establish what is the safest and most advisable procedure. We noted that the type of resection was subordinated to the clinical characteristics of patients rather than the oncological effectiveness of method. This is clearly a bias as there is a risk of comparing patients and not techniques. In fact, the different methods should only be evaluated in homogeneous groups of patients in which each technique can be freely and safely used. Starting from these considerations (the non-mandatory nature of the type of procedure) we did not find in literature any data that would allow a correct meta-analysis.

Furthermore, many studies do not provide complete data on the incidence of complications or of relapses relating to the different approaches. All this explains the difficulty of performing statistical analysis and the impossibility 


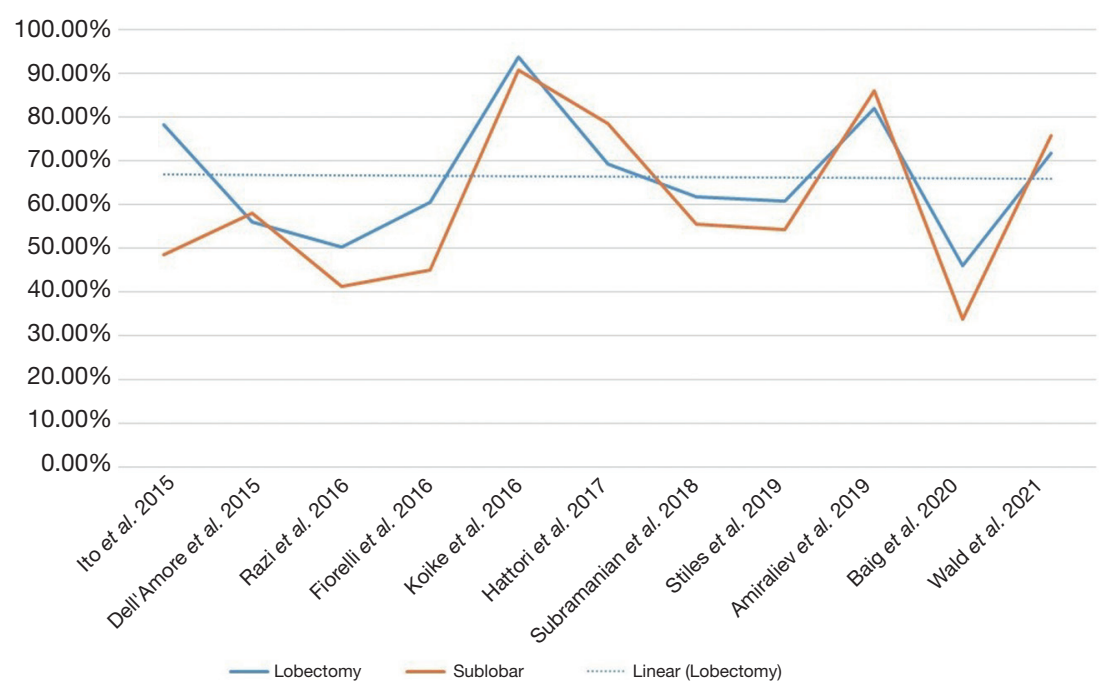

Figure 4 Comparison of the survival curves for lobectomies and sublobar resection.

of proceeding with a meta-analysis. Based on these considerations, we believe that multicentre randomized studies, with clear primary and secondary end points, are necessary in order to acquire homogeneous and comparable data in a large number of patients. This would allow for a meta-analysis on meaningful data in order to define future guidelines about the recommended surgical methods for early-stage NSCLC.

\section{Conclusions}

From the evaluation of the literature and from the statistical analysis of the data we believe that lobectomy still represents the oncologically safest and effective technique to treat early-stage NSCLC. Currently, sublobar resection is a valid alternative to lobectomy in selected cases. The increased experience of minimally invasive approaches and of lung resections with parenchymal sparing shows that good results can be achieved in the short-term and mediumterm follow-up. The long-term validity of anatomical segmentectomy and/or wedge resection need further specific and comparable randomized control trials.

\section{Acknowledgments}

Funding: None.

\section{Footnote}

Provenance and Peer Review: This article was commissioned by the editorial office, AME Surgical Fournal for the series "Solitary Pulmonary Nodule". The article has undergone external peer review.

Reporting Checklist: The authors have completed the Narrative Review reporting checklist. Available at https:// asj.amegroups.com/article/view/10.21037/asj-21-31/rc

Conflicts of Interest: All authors have completed the ICMJE uniform disclosure form (available at https://asj.amegroups. com/article/view/10.21037/asj-21-31/coif). The series "Solitary Pulmonary Nodule" was commissioned by the editorial office without any funding or sponsorship. DD served as an unpaid Guest Editor of the series and serves as an unpaid editorial board member of AME Surgical fournal from January 2021 to December 2022. The authors have no other conflicts of interest to declare.

Ethical Statement: The authors are accountable for all aspects of the work in ensuring that questions related to the accuracy or integrity of any part of the work are appropriately investigated and resolved.

Open Access Statement: This is an Open Access article distributed in accordance with the Creative Commons Attribution-NonCommercial-NoDerivs 4.0 International License (CC BY-NC-ND 4.0), which permits the noncommercial replication and distribution of the article with the strict proviso that no changes or edits are made and the original work is properly cited (including links to both the 
formal publication through the relevant DOI and the license). See: https://creativecommons.org/licenses/by-nc-nd/4.0/.

\section{References}

1. Wang L, Ma Q, Yao R, et al. Current status and development of anti-PD-1/PD-L1 immunotherapy for lung cancer. Int Immunopharmacol 2020;79:106088.

2. Takada K, Toyokawa G, Shoji F, et al. The Significance of the PD-L1 Expression in Non-Small-Cell Lung Cancer: Trenchant Double Swords as Predictive and Prognostic Markers. Clin Lung Cancer 2018;19:120-9.

3. Xu Y, Wan B, Chen X, et al. The association of PD$\mathrm{L} 1$ expression with the efficacy of anti-PD-1/PD-L1 immunotherapy and survival of non-small cell lung cancer patients: a meta-analysis of randomized controlled trials. Transl Lung Cancer Res 2019;8:413-28.

4. Norman K, Klaus S. Veganism, aging and longevity: new insight into old concepts. Curr Opin Clin Nutr Metab Care 2020;23:145-50.

5. Vaupel JW. Biodemography of human ageing. Nature 2010;464:536-42.

6. Bédat B, Abdelnour-Berchtold E, Perneger T, et al. Comparison of postoperative complications between segmentectomy and lobectomy by video-assisted thoracic surgery: a multicenter study. J Cardiothorac Surg 2019;14:189.

7. Tsutani $Y$, Kagimoto A, Handa $Y$, et al. Wedge resection versus segmentectomy in patients with stage I non-smallcell lung cancer unfit for lobectomy. Jpn J Clin Oncol 2019;49:1134-42.

8. Divisi D, Imbriglio G, De Vico A, et al. Lung nodule management: a new classification proposal. Minerva Chir 2011;66:223-34.

9. Lopes Pegna A, Picozzi G, Falaschi F, et al. Four-year results of low-dose CT screening and nodule management in the ITALUNG trial. J Thorac Oncol 2013;8:866-75.

10. Munden RF, Chiles C, Boiselle PM, et al. Micronodules Detected on Computed Tomography During the National Lung Screening Trial: Prevalence and Relation to Positive Studies and Lung Cancer. J Thorac Oncol 2019;14:1538-46.

11. Landreneau RJ, Schuchert MJ. Is segmentectomy the future? J Thorac Dis 2019;11:308-18.

12. Landreneau RJ, Sugarbaker DJ, Mack MJ, et al. Wedge resection versus lobectomy for stage I (T1 N0 M0) non-small-cell lung cancer. J Thorac Cardiovasc Surg 1997;113:691-8; discussion 698-700.
13. Im DJ, Lee SM, Han K, et al. Predictive factors of recurrence after resection of subsolid clinical stage IA lung adenocarcinoma. Thorac Cancer 2021;12:941-8.

14. Wald O, Sadeh BM, Bdolah-Abram T, et al. Outcomes of sublobar resection vs lobectomy for invasive clinical stage T1N0 non-small-cell lung cancer: A propensity-match analysis. Cancer Rep (Hoboken) 2021;4:e1339.

15. Dong B, Zhu X, Jin J, et al. Comparison of the outcomes of sublobar resection and stereotactic body radiotherapy for stage T1-2N0M0 non-small cell lung cancer with tumor size $\leq 5 \mathrm{~cm}$ : a propensity score matching analysis. J Thorac Dis 2020;12:5934-54.

16. Baig MZ, Razi SS, Weber JF, et al. Lobectomy is superior to segmentectomy for peripheral high grade non-small cell lung cancer $\leq 2 \mathrm{~cm}$. J Thorac Dis 2020;12:5925-33.

17. Zhang J, Bai W, Guo C, et al. Postoperative Short-term Outcomes Between Sublobar Resection and Lobectomy in Patients with Lung Adenocarcinoma. Cancer Manag Res 2020;12:9485-93.

18. Chang CC, Yen YT, Lin CY, et al. Single-port videoassisted thoracoscopic surgery subsegmentectomy: The learning curve and initial outcome. Asian J Surg 2020;43:625-32.

19. Amiraliev AM, Pikin OV, Ryabov AB, et al. Segmentectomy in patients with primary pulmonary malignancies. Khirurgiia (Mosk) 2019;(10):5-12.

20. Kamigaichi A, Tsutani Y, Fujiwara M, et al. Postoperative Recurrence and Survival After Segmentectomy for Clinical Stage 0 or IA Lung Cancer. Clin Lung Cancer 2019;20:397-403.e1.

21. Stiles BM, Mao J, Harrison S, et al. Sublobar resection for node-negative lung cancer $2-5 \mathrm{~cm}$ in size. Eur J Cardiothorac Surg 2019;56:858-66.

22. Yang H, Li X, Shi J, et al. A nomogram to predict prognosis in patients undergoing sublobar resection for stage IA non-small-cell lung cancer. Cancer Manag Res 2018;10:6611-26.

23. Ali J, Haiyang F, Aresu G, et al. Uniportal Subxiphoid Video-Assisted Thoracoscopic Anatomical Segmentectomy: Technique and Results. Ann Thorac Surg 2018;106:1519-24.

24. Yendamuri S, Dhillon SS, Groman A, et al. Effect of the number of lymph nodes examined on the survival of patients with stage I non-small cell lung cancer who undergo sublobar resection. J Thorac Cardiovasc Surg 2018;156:394-402.

25. Subramanian M, McMurry T, Meyers BF, et al. LongTerm Results for Clinical Stage IA Lung Cancer: 
Comparing Lobectomy and Sublobar Resection. Ann Thorac Surg 2018;106:375-81.

26. Brandt WS, Bouabdallah I, Tan KS, et al. Factors associated with distant recurrence following R0 lobectomy for $\mathrm{pN} 0$ lung adenocarcinoma. J Thorac Cardiovasc Surg 2018;155:1212-1224.e3.

27. Moon Y, Lee KY, Park JK. Margin Width of Resected Lepidic Lung Cancer Does Not Affect Recurrence After Sublobar Resection. World J Surg 2018;42:1449-57.

28. Gossot D, Lutz JA, Grigoroiu M, et al. Unplanned Procedures During Thoracoscopic Segmentectomies. Ann Thorac Surg 2017;104:1710-7.

29. Tsunezuka H, Kato D, Okada S, et al. Surgical outcome of wide wedge resection in poor-risk patients with clinical-N0 non-small cell lung cancer. Gen Thorac Cardiovasc Surg 2017;65:581-6.

30. Hattori A, Matsunaga T, Takamochi K, et al. Surgical resection for clinical-Stage I radiological pure-solid lung cancer that met the current high risk criteria. Jpn J Clin Oncol 2017;47:630-8.

31. Koike T, Koike T, Sato S, et al. Lobectomy and limited resection in small-sized peripheral non-small cell lung cancer. J Thorac Dis 2016;8:3265-74.

32. Echavarria MF, Cheng AM, Velez-Cubian FO, et al. Comparison of pulmonary function tests and perioperative outcomes after robotic-assisted pulmonary lobectomy vs segmentectomy. Am J Surg 2016;212:1175-82.

33. Fiorelli A, Caronia FP, Daddi N, et al. Sublobar resection versus lobectomy for stage I non-small cell lung cancer: an appropriate choice in elderly patients? Surg Today 2016;46:1370-82.

34. Gulack BC, Yang CJ, Speicher PJ, et al. A Risk Score to Assist Selecting Lobectomy Versus Sublobar Resection for Early Stage Non-Small Cell Lung Cancer. Ann Thorac Surg 2016;102:1814-20.

35. Dai C, Shen J, Ren Y, et al. Choice of Surgical Procedure for Patients With Non-Small-Cell Lung Cancer $\leq 1 \mathrm{~cm}$ or $>1$ to $2 \mathrm{~cm}$ Among Lobectomy, Segmentectomy, and Wedge Resection: A Population-Based Study. J Clin Oncol 2016;34:3175-82.

36. Kent MS, Mandrekar SJ, Landreneau R, et al. A Nomogram to Predict Recurrence and Survival of HighRisk Patients Undergoing Sublobar Resection for Lung Cancer: An Analysis of a Multicenter Prospective Study (ACOSOG Z4032). Ann Thorac Surg 2016;102:239-46.

37. Razi SS, John MM, Sainathan S, et al. Sublobar resection is equivalent to lobectomy for T1a nonsmall cell lung cancer in the elderly: a Surveillance,
Epidemiology, and End Results database analysis. J Surg Res 2016;200:683-9.

38. Hattori A, Takamochi K, Matsunaga T, et al. Oncological outcomes of sublobar resection for clinical-stage IA high-risk non-small cell lung cancer patients with a radiologically solid appearance on computed tomography. Gen Thorac Cardiovasc Surg 2016;64:18-24.

39. Kim D, Ferraris VA, Davenport D, et al. Outcomes of lobar and sublobar resections for non-small-cell lung cancer: a single-center experience. South Med J 2015;108:230-4.

40. Dell'Amore A, Monteverde M, Martucci N, et al. Lobar and sub-lobar lung resection in octogenarians with early stage non-small cell lung cancer: factors affecting surgical outcomes and long-term results. Gen Thorac Cardiovasc Surg 2015;63:222-30.

41. Ito H, Nakayama H, Yamada K, et al. Outcomes of lobectomy in 'active' octogenarians with clinical stage I non-small-cell lung cancer. Ann Thorac Cardiovasc Surg 2015;21:24-30.

42. Gaudet MA, D'Amico TA. Thoracoscopic Lobectomy for Non-small Cell Lung Cancer. Surg Oncol Clin N Am 2016;25:503-13.

43. Speicher PJ, Gu L, Gulack BC, et al. Sublobar Resection for Clinical Stage IA Non-small-cell Lung Cancer in the United States. Clin Lung Cancer 2016;17:47-55.

44. Cohen C, Al Orainy S, Pop D, et al. Anatomical pulmonary resections for primary lung cancer in octogenarians within a dedicated care protocol. J Thorac Dis 2019;11:3732-7.

45. Liu T, Liu H, Li Y. Early lung cancer in the elderly: sublobar resection provides equivalent long-term survival in comparison with lobectomy. Contemp Oncol (Pozn) 2014;18:111-5.

46. Shiono S, Endo M, Suzuki K, et al. Spread Through Air Spaces Is a Prognostic Factor in Sublobar Resection of Non-Small Cell Lung Cancer. Ann Thorac Surg 2018;106:354-60.

47. Liu H, Yin Q, Yang G, et al. Prognostic Impact of Tumor Spread Through Air Spaces in Non-small Cell Lung Cancers: a Meta-Analysis Including 3564 Patients. Pathol Oncol Res 2019;25:1303-10.

48. Kadota K, Nitadori JI, Sima CS, et al. Tumor Spread through Air Spaces is an Important Pattern of Invasion and Impacts the Frequency and Location of Recurrences after Limited Resection for Small Stage I Lung Adenocarcinomas. J Thorac Oncol 2015;10:806-14. 
49. Cao C, Chandrakumar D, Gupta S, et al. Could less be more?-A systematic review and meta-analysis of sublobar resections versus lobectomy for non-small cell lung cancer according to patient selection. Lung Cancer 2015;89:121-32.

doi: 10.21037/asj-21-31

Cite this article as: Divisi D, De Vico A, Aquilini P, Zaccagna G. Lobectomy or sublobar resection?-comparative analysis of the techniques in the surgical treatment of non-small cell lung cancer: a narrative review. AME Surg J 2021;1:25.
50. Zhang Y, Sun Y, Wang R, et al. Meta-analysis of lobectomy, segmentectomy, and wedge resection for stage I non-small cell lung cancer. J Surg Oncol 2015;111:334-40. 